\title{
The efficacy of Tc-99m DMSA scintigraphy in children with vesicoureteral reflux accompanying frequent urinary tract infection
}

\author{
Mehmet Emin Celikkaya ${ }^{1}$, Ahmet Atici $^{1}$, Hasan Ikbal Atilgan ${ }^{2}$ \\ ${ }^{1}$ Department of Pediatric Surgery, Faculty of Medicine, Mustafa Kemal University, Hatay, Turkey \\ ${ }^{2}$ Department of Nuclear Medicine, Faculty of Medicine, Mustafa Kemal University, Hatay, Turkey \\ Received: 22 July 2019, Accepted: 20 August 2019, Published online: 31 December 2019 \\ (C) Ordu University Institute of Health Sciences, Turkey, 2019
}

\begin{abstract}
Objective: Urinary tract infection is one of the most common diseases in childhood. Experimental studies have shown that renal damage due to urinary tract infection can be prevented by early diagnosis and treatment. The aim of this study was to evaluate the correlation between vesicoureteral reflux grade and Technetium-99m- dimercaptosuccinic acid scintigraphy in patients with frequent urinary tract infection Methods Between January and October 2017, 34 cases were diagnosed as vescoureteral reflux with voiding cystoureterography were retrospectively evaluated with Technetium-99m- dimercaptosuccinic acid scintigraphy in terms of renal scar and function. Scars and function ratios were evaluated in Technetium$99 \mathrm{~m}$ - dimercaptosuccinic acid scintigraphy according to voiding cystourethrography grades and correlation between the vesicoureteral reflux grade and Technetium-99m- dimercaptosuccinic acid scintigraphy findings were investigated.

Results: Of 34 patients, 26 (76.5\%) were female and 8 (23.5\%) were male. The mean age of the patients was $6.08 \pm 4.03$ (min: 1 month, max: 17 years). Twenty-one patients had unilateral vesicoureteral reflux and 13 patients had bilateral vesicoureteral reflux. Vesicoureteral reflux were detected in 47 of the total 68 kidneys. Conclusion: In children with vesicoureteral reflux, Technetium-99m- dimercaptosuccinic acid scintigraphy provides useful information to show the kidney damage and as the vesicoureteral reflux grade increases, the rate of kidney damage increases. Even in the case of grade 1 and grade 2 vesicoureteral reflux, which are not expected to cause renal parenchymal damage. Technetium-99m- dimercaptosuccinic acid scintigraphy is the most successful imaging method for detecting parenchymal injury.
\end{abstract}

Key words: DMSA; Vesicoureteral Reflux; Voiding Cystoureterography

Suggested Citation: Celikkaya ME, Atici A, Atilgan Hİ. The efficacy of Tc-99m DMSA scintigraphy in children with vesicoureteral reflux accompanying frequent urinary tract infection. Middle Black Sea Journal of Health Science, 2019; 5(3):252-260

Address for correspondence/reprints:

Mehmet Emin Celikkaya

Telephone number: +90 (537) 3324143

E-mail: eminctf@hotmail.com

DOI: $\quad 10.19127 /$ mbsjohs.616799
Note: This paper was presented as an oral presentation at the Dr. Behçet Uz Children's Congress between February 28 and March 2, 2019. 


\section{Introduction}

Urinary tract infection is one of the most common diseases in childhood. This infection can only be limited to the bladder (cystitis) or may result in renal parenchymal injury (pyelonephritis) (Tekgul et al., 2012). The risk of developing renal parenchymal injury has increased, especially in children with high degrees of vesicoureteral reflux (VUR) (Temiz et al., 2006). Therefore, if VUR is not excluded in children with frequent urinary tract infections (more than two in six months, three or more in one year), end stage renal failure may be developed in these patients. In all children who have a frequent urinary tract infection and the children who have a febrile urinary tract infection under 2 years of age, voiding cystourethrography (VCUG) is recommended. Experimental studies have shown that renal damage due to urinary tract infection can be prevented by early diagnosis and treatment (Hoberman et al., 2003). Therefore, detection of VUR and renal scar is of great importance. The sensitivity of Technetium-99m dimercaptosuccinic acid (Tc-99m DMSA) scintigraphy in detection acute and chronic pyelonephritis is higher than intravenous pyelography and ultrasonography (Stokland et al., 1999). In addition, it is considered the gold standard for the detection of renal scar (Bhatnagar et al., 2002; Piepsz et al., 1999). The aim of this study is to emphasize the importance of Tc$99 \mathrm{~m}$ DMSA scintigraphy in evaluating the relationship between VUR grade and renal parenchymal injury in patients with VUR.

\section{Methods}

\section{Design of the study}

34 patients aged 0-18 years with vesicoureteral reflux were included in the study. These children who admitted to Hatay Mustafa Kemal University Pediatric Surgery Clinic between January and October 2017 were evaluated retrospectively. All patients presented with frequent urinary tract infection (more than two in six months, three or more in one year) and were diagnosed VUR via VCUG.

With the decision dated 11.10.2018 and numbered 12, ethics committee approval was obtained. Antibiotic prophylaxis was initiated in all patients diagnosed with VUR and Tc-99m DMSA scintigraphy was performed after there was no growth in urine cultures. Patient's VUR grades and also defected/hypoperfused areas and renal functions in Tc-99 mm DMSA scintigraphy were recorded.
Tc-99m DMSA scintigraphy capture

After obtaining informed consent from the parents of the patient, Tc-99m DMSA was administered intravenously at a dose of $1-5 \mathrm{mCi}$ according to the age of the patient. Three hours later, the two-headed gamma camera (Siemens, Symbia S, Germany) and static images were taken at posterior, anterior and posterior oblique positions. Images were taken with low energy general purpose collimator in $256 \times 256$ matrix using $140 \mathrm{keV} \pm$ energy window. 1000 kkount count was taken for each position.

Scars and function ratios were evaluated in Tc$99 \mathrm{~m}$ DMSA scintigraphy according to VCUG grades and correlation between the VUR grade and Tc-99m DMSA scintigraphy findings were investigated.

\section{Statistical analysis}

Data were analyzed using Statistical Pack for Social Science for Windows 18.0 version. (SPSS Inc., Chicago, IL, USA). Quantitative data were assessed were examined by student's $t$ test. Qualitative data were evaluated by ki Chi-square test. $\mathrm{P}<0.05$ was considered significant.

\section{Results}

Of the 34 patients, $26(76.5 \%)$ were female and $8(23.5 \%)$ were male. The mean age of the patients was $6.08 \pm 4.03$ (min: 1 month, max: 17 years). Twenty-one patients had unilateral VUR and 13 patients had bilateral VUR. VUR was detected in 47 of the 68 kidneys in total (Table 1). There were 7 kidneys with grade 1, 5 kidneys grade 2, 16 kidneys with grade 3, 15 kidneys with grade 4, and 4 kidneys with grade 5 VUR (Table 2).

Table 1. Clinical features of patients

\begin{tabular}{crc}
\hline & $\mathbf{n}$ & $\%$ \\
\hline Number of Patients & 34 & \\
\hline Male & 8 & 76.5 \\
\hline Female & 26 & 23.5 \\
\hline Mean age all of the patients & 6,08 & \\
\hline Male & 5,4 & \\
\hline Female & 6,28 & \\
\hline Side of vesicoureteral reflux & & \\
\hline Left & 9 & 26,47 \\
\hline Right & 12 & 35,29 \\
\hline Bilateral & 13 & 38,23 \\
\hline Mean function (\%) & & \\
\hline On the VUR side & 35 & \\
\hline On the non VUR side & 64,64 & \\
\hline
\end{tabular}


Table 2. The number of kidneys according to vesicoureteral reflux grades

\begin{tabular}{cc}
\hline VUR Grade & $\begin{array}{c}\text { The number of kidney } \\
(\mathrm{n}=47)\end{array}$ \\
\hline Grade 1 & 7 \\
Grade 2 & 5 \\
Grade 3 & 16 \\
Grade 4 & 15 \\
Grade 5 & 4 \\
\hline
\end{tabular}

Mean age of patients with grade 1 reflux was 4 , patients with grade 2 reflux was 5 , patients with grade 3 reflux was 7.25 , patients with grade 4 reflux was 5.8, patients with gr5 reflux was 8 . One patient with grade 5 reflux was 1 month old.

The mean function on the VUR side of 21 patients with unilateral VUR was $35.36 \pm 16.33 \%$ and the mean function on the non-VUR side was $64.64 \pm 16.33 \%$. Of the 47 kidneys with VUR, 25 kidneys had cortical defect / hypoperfusion. While there is no pathology in 22 kidneys; perfusion defect were observed globally in 14 kidneys, on the upper pole in 4 kidneys, on the both upper and lower poles in 4 kidneys, on the lower pole in 2 kidneys and on the both upper pole and the middle section in 1 kidney (Table 3) (Figure 1).

Table 3. The number of kidneys with vesicoureteral reflux and perfusion defect; and also localization of defects

\begin{tabular}{cc}
\hline Defect localization & $\begin{array}{c}\text { The number of kidney } \\
(\mathrm{n}=47)\end{array}$ \\
\hline Normal (no defect) & 22 \\
Global & 14 \\
Upper pole & 4 \\
Upper and lower pole & 4 \\
Lower pole & 2 \\
Upper pole and central & 1 \\
part & \\
\hline
\end{tabular}

The incidence of perfusion defects was $14.3 \%$ in grade 1 VUR, $40 \%$ in grade 2 VUR, $43.7 \%$ in grade 3 VUR, $73.3 \%$ in grade 4 VUR and $100 \%$ in grade 5 VUR (Table 4). In low-grade VUR (Grade 1 and 2 ), the incidence of perfusion defects in the kidneys was $25 \%$, while in the high-grade VUR (Grade 3 and above) was $62.86 \%$. Scar function increases significantly as the degree of VUR increases. $\mathrm{P}:<0.28$ ( 1 and 5$)$
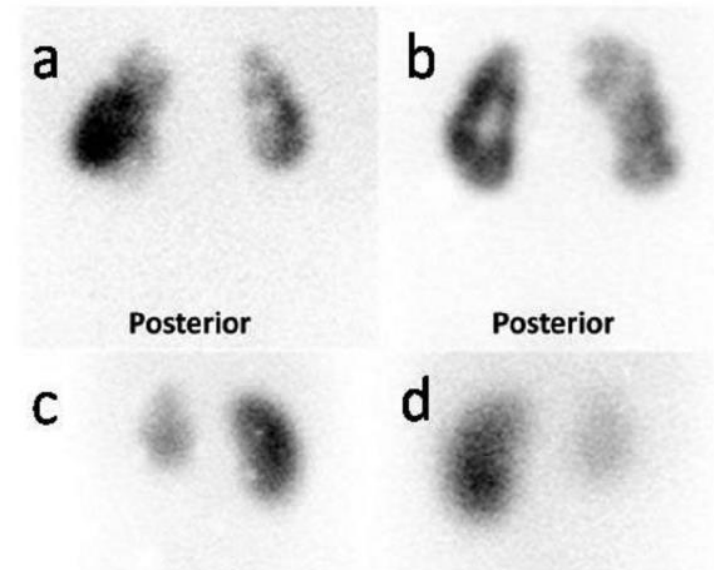

Posterior

Anterior

Figure 1. 9-year-old girl, multiple defects in both kidneys, more prominent on the right, function rates were $74 \%$ in left kidney, $26 \%$ in right kidney, and grade 4 VUR in bilateral kidneys (a), 2-year-old girl, multiple defects in both kidneys, more prominent on the right, function rates left kidney 51\%, right kidney $49 \%$, bilateral kidneys grade 4 VUR (b), 5-year-old girl, global hypoperfusion in the left kidney, function rates in the left kidney $17 \%$, right kidney $83 \%$, left kidney grade 3 VUR, posterior image (c), anterior view of the same patient (d).

Table 4. Rates of perfusion defects in kidneys according to vesicoureteral reflux grade

\begin{tabular}{cccc}
\hline $\begin{array}{c}\text { VUR } \\
\text { Grade }\end{array}$ & $\begin{array}{c}\text { Number } \\
\text { of kidney } \\
\text { with } \\
\text { defect }\end{array}$ & $\begin{array}{c}\text { Number of } \\
\text { kidney } \\
\text { without } \\
\text { defect }\end{array}$ & $\begin{array}{c}\text { Percentage } \\
\text { of perfusion } \\
\text { defects }\end{array}$ \\
\hline Grade 1 & 1 & 6 & $\% 14,3$ \\
\hline Grade 2 & 2 & 3 & $\% 40$ \\
\hline Grade 3 & 7 & 9 & $\% 43,7$ \\
\hline Grade 4 & 11 & 4 & $\% 73,3$ \\
\hline Grade 5 & 4 & 0 & $\% 100$ \\
\hline
\end{tabular}

\section{Discussion}

Vesicoureteral reflux is the most common anomaly in pediatric urinary tract infections (Y1lmaz et al., 2018). The rate of VUR diagnosis in children with frequent urinary tract infections has been reported to be 30-50\% (Simsek et al., 1991). VUR is the most common risk factor in the development of renal damage (Camacho et al., 2004), resulting in renal parenchymal damage as well as proteinuria, hypertension and end-stage renal failure in children (Peters et al., 2010). 
Diagnosis, treatment and follow-up of these patients are very important and children with frequently urinary tract infection should be investigated for VUR. Because, if the early diagnosis of VUR can be made and treated, the renal function of these patients can be preserved.

The presence of renal scarring is a most critical determinant factor in the surgical treatment of VUR. Intravenous pyelography (IVP) was the most commonly used method for evaluating renal parenchyma before radionuclide imaging methods developed. In low grade VUR's where pelvicaliseal dilatation is not observed, IVP can be mostly normal. In addition, it was reported that 6 to 24 month period was required for renal damage to be seen in the IVP. Renal damage can be detected much earlier via Tc-99m DMSA scintigraphy (Rushton et al., 1992). Ultrasonography is the most commonly used imaging method for this purpose because of its cheap, easily accessible and no radiation. However, Tc-99m DMSA scintigraphy is much more sensitive in detecting parenchymal defects, It has been reported that USG cannot detect $40 \%$ of scars and these renal scars can be detected by Tc-99m DMSA scintigraphy (Temiz et al., 2006). Therefore, Tc-99m DMSA scintigraphy has been accepted as the gold standard in detecting the presence of renal scar (Roebuck et al., 1999).

The indications of Tc-99m DMSA scintigraphy is detection of renal parenchymal abnormalities, renal sequelae (six months after infection), acute pyelonephritis, associated abnormalities (abnormal duplex kidney, small kidney, dysplastic tissue, horseshoe kidney), ectopic kidney and confirmation of non-functional multicystic kidney. There are no contraindications for Tc-99m DMSA scintigraphy. During the acquisition, immobilization of the child should be obtained. The most difficult age is between 1-3 years, but sedation is rarely needed. Tc99m MAG3 scintigraphy can also be used to detect renal parenchymal defects, but Tc-99m MAG3 scintigraphy images are acquired only in posterior or anterior and posterior positions without oblique positions. You do not have a second chance to take the images again with Tc-99m MAG3 scintigraphy, because it is a dynamic acquisition. But in Tc-99m DMSA scintigraphy, the technician can acquire the images again in case of any problem such as patient movement.

In case of significant hydronephrosis late Tc$99 \mathrm{~m}$ DMSA images (4 to 24 hours) or diuretic injection may be useful to excrete Tc-99m DMSA activity from the renal pelvis. In these cases Tc-99m
MAG3 scintigraphy should be considered (Piepsz et al., 2009).

It can detect acute pyelonephritis if it is used during the acute illness, but it shows renal scars secondary to acute disease in late imaging performed months after infection (Wani et al., 2016). In Tc-99m DMSA scintigraphy, wedgeshaped cortical defects and decreased renal volume associated with decreased cortical function are significant for determining renal scarring (Agras et al., 2007). In a study recommended that all children with recurrent urinary tract infections should be routinely investigated for VUR via VCUG in addition to USG and DMSA scintigraphy should be performed in non-acute period (Doğan et al., 2018). Wongbencharat et al found that the sensitivity of urinary tract infection was 50\% and Tc-99m DMSA scintigraphy in the sixth month was $87.5 \%$ in predicting infants with high grade VUR (Wongbencharat et al.,2016).

Awais et al reported that Tc-99m DMSA scintigraphy has high sensitivity and negative predictive value on patients with high grade VUR (Grade 3 and higher) and also it has benefit of exclusion of high grade VUR (Awais et al., 2015). In our study, as the VUR grade increased, the probability of renal damage in the kidneys was increased. The incidence of perfusion defect in low grade VUR was $25 \%$, whereas it was $62.86 \%$ in high-grade VUR. Urinary tract infection accompanied fever do not cause renal damage in most children, even if the resulting damage it is generally remains unchanged or recedes over time. However, $20 \%$ of children with kidney damage after urinary tract infection have impaired renal function. Patients with impaired renal function are usually children with grade 3-5 VUR (Swerkersson et al., 2017). There is a direct correlation between renal scar development and VUR grade (Temiz et al., 2006). In our study, the frequency of perfusion defect / scar development in the kidneys increased as the VUR degree increased. An important point was that no pathology was found in 22 (46.80\%) of 47 kidneys with VUR. An important point was that no pathology was found in $22(46.80 \%)$ of 47 kidneys with VUR. This result supports the hypothesis that if there is no observed pathology in the TC-99m scintigraphy in early period, the risk of developing renal scar is low (Biggi et al., 2001; Stockland et al., 1996).

\section{Conclusion}

Vesicoureteral reflux is an important cause of chronic renal failure in children if it is not diagnosed 
and treated in time. The severity of the renal parenchymal injury should be evaluated after the diagnosis of VUR. In children with VUR, Tc-99m DMSA scintigraphy provides useful information to show the renal damage and as the VUR grade increases, the rate of renal damage increases. Even in the case of grade 1 and grade 2 VUR, which are not expected to cause renal parenchymal damage. Tc-99m DMSA scintigraphy is the most successful imaging method for detecting parenchymal injury, which can detect early damage with less radiation exposure.

Ethics Committee Approval: Ethics committee approval was received for this study from Clinical Research Ethics Committee of Hatay Mustafa Kemal University (2018-12).

Peer-review: Externally peer-reviewed.

Author Contributions: Concept - MEC, HIA; Design MEC, AA; Supervision MEC, HIA; Materials HIA; Data Collection and/or Processing Hİ; Analysis and/or Interpretation- MEC; Literature Review - HIA, AA; Writing - MEC, AA, HIA; Critical Review - MEC, HIA.

Conflict of Interest: No conflict of interest was declared by the author.

Financial Disclosure: The authors declared that this study hasn't received no financial support.

\section{References}

Agras K, Ortapamuk H, Naldoken S, Tuncel A, Atan A. Resolution of cortical lesions on serial renal scans in children with acute pyelonephritis. Pediatr Radiol. 2007 Feb;37(2):153-8.

Awais M, Rehman A, Zaman MU, Nadeem N. Recurrent urinary tract infections in young children: role of DMSA scintigraphy in detecting vesicoureteric reflux. Pediatr Radiol. 2015 Jan;45(1):62-8.

Bhatnagar V, Mitra D, Agarwala S, Kumar R, Patel $\mathrm{C}$, Malhotra A, et al. The role of DMSA scans in evaluation of the correlation between urinary tract infection, vesicoureteric reflux, and renal scarring. Pediatric surgery international. 2002;18(2-3):128-34.

Biggi A, Dardanelli L, Cussino P, Pomero G, Noello C, Sernia O, et al. Prognostic value of the acute DMSA scan in children with first urinary tract infection. Pediatric Nephrology. 2001;16(10):800-4.

Camacho V, Estorch M, Fraga G, Mena E, Fuertes J, Hernandez M, et al. DMSA study performed during febrile urinary tract infection: a predictor of patient outcome? European journal of nuclear medicine and molecular imaging. 2004;31(6):862-6.

Dogan CS, Koyun NS, Aksoy GK, Cekic B, Savas M, Comak E. Delayed diagnosis of primary vesicoureteral reflux in children with recurrent urinary tract infections: Diagnostic approach and renal outcomes. Turk J Urol. 2018 Nov;44(6):498-502.

Hoberman A, Charron M, Hickey RW, Baskin M, Kearney DH, Wald ER. Imaging studies after a first febrile urinary tract infection in young children. New England Journal of Medicine. 2003;348(3):195-202.

Hodson C, Maling T, McManamon PJ, Lewis M. The pathogenesis of reflux nephropathy (chronic atrophic pyelonephritis). The British journal of radiology. 1975:1-26.

Peters CA, Skoog SJ, Arant BS, Copp HL, Elder JS, Hudson RG, et al., Snodgrass, W. T. Summary of the AUA guideline on management of primary vesicoureteral reflux in children. The Journal of urology. 2010; 184(3), 1134-1144.

Piepsz A, Blaufox M, Gordon I, Granerus G, Majd M, O'reilly P, et al., editors. Consensus on renal cortical scintigraphy in children with urinary tract infection. Seminars in nuclear medicine; 1999: Elsevier.

Piepsz A, Colarinha P, Gordon I, Hahn K, Olivier $\mathrm{P}$, Roca I , et al. European Association of Nuclear Medicine. Guidelines on 99mTcDMSA scintigraphy in children 2009 ;39: 15673

Roebuck D, Howard R, Metreweli C. How sensitive is ultrasound in the detection of renal scars? The British journal of radiology. 1999;72(856):3458.

Rushton HG. Urinary tract infections in children: epidemiology, evaluation, and management. Pediatric Clinics of North America. 1997;44(5):1133-69.

Tekgul S, Riedmiller H, Hoebeke P, Kocvara R, Nijman RJ, Radmayr C., et al., EAU guidelines on vesicoureteral reflux in children. European urology, 2012; 62(3), 534-542.

Stokland E, Hellstrom M, Jacobsson B, Sixt R. Imaging of renal scarring. Acta Paediatrica. 1999;88:13-21. 
Stokland E, Hellstrom M, Jacobsson B, Jodal U, Lundgren P, Sixt R. Early 99mTc dimercaptosuccinic acid (DMSA) scintigraphy in symptomatic first-time urinary tract infection. Acta Paediatrica. 1996;85(4):430-6.

Swerkersson S, Jodal U, Sixt R, Stokland E, Hansson S. Urinary tract infection in small children: the evolution of renal damage over time. Pediatr Nephrol. 2017 Oct;32(10):19071913.

Simsek F, Ilker Y, Akdas A, Türkeri L. Teflon injection in the treatment of vesicoureteral reflux: a promising alternative for surgery. International urology and nephrology. 1991;23(1):27-30.

Temiz Y, Tarcan T, Onol F, Alpay H, Şimşek F. The efficacy of Tc99m dimercaptosuccinic acid (TcDMSA) scintigraphy and ultrasonography in detecting renal scars in children with primary vesicoureteral reflux (VUR). International Urology and Nephrology. 2006;38(1):149-52.

Wani KA, Ashraf M, Bhat JA, Parry NA, Shaheen L, Bhat SA. Paediatric Urinary Tract Infection: A Hospital Based Experience. J Clin Diagn Res. 2016 Oct;10(10):SC04-SC07.

Wongbencharat K, Tongpenyai Y, Na-Rungsri K. Renal ultrasound and DMSA screening for highgrade vesicoureteral reflux. Pediatr Int. 2016 Mar;58(3):214-8.

Yılmaz I, Peru H, Yilmaz FH, Sekmenli T, Ciftci I, Kara F. Association of vesicoureteral reflux and renal scarring in urinary tract infections. Arch Argent Pediatr. 2018 Aug 1;116(4):e542-e547. 